УДК 338.012

РОЛЬ ИНТЕГРАЦИОННЫХ ОБЬЕДИНЕНИЙ В ЭКОНОМИКЕ СТРАНЫ

Чириканова Е.А.

ФГБОУ ВО «Московский автомобильно-дорожный государственный технический университет (МАДИ)»,e-mail: chirikanova@mail.ru

\begin{abstract}
В статье рассматриваются вопросы международной экономической интеграции в мире и в России, которая стала возможностью ускоренного экономического развития региональных экономик. Возрастающее количество новых интеграционных объединений подтверждает, что такой механизм в целом приводит к положительному эффекту, как для страны-участника, так и для хозяйствующего субъекта. Предпосылкой для основы таких объединений является перспектива улучшения экономических результатов стран-участников, за счет взаимовыгодного сотрудничества. Евразийский экономический союз ведет свою деятельность относительно недавно и представляет интерес не только соседних с ним стран, но со стороны всего международного сообщества. В работе рассматриваются вопросы и перспективы развития Евразийского экономического союза. В сложившейся ситуации анализ проблем, факторов, оказывающих наибольшее влияние на развитие экономического сотрудничества стран Евразийского экономического союза, является актуальным. В работе отмечается, что в области внешней торговли Евразийского экономического союза наблюдается значительный спад торгового оборота. Можно сделать вывод, что наблюдается отдельное количественное увеличение показателей экономического сотрудничества стран-участников, но при этом недостаточно оснований для долгосрочного стабильного экономического развития этих взаимоотношений. Потенциал Евразийского экономического союза не используется в той мере, в которой это было бы возможно, и опыт других стран нам это подтверждает.
\end{abstract}

Ключевые слова: развитие, интеграция, ЕАЭС, экономический рост, сотрудничество

\title{
THE ROLE OF INTEGRATION ASSOCIATIONS IN THE ECONOMY OF THE COUNTRY
}

\author{
Chirikanova E.A. \\ Moscow Automobile and Road Technical State University (MADI), Moscow, e-mail: chirikanova@mail.ru
}

\begin{abstract}
The article deals with issues of international economic integration in the world and in Russia, which has become an opportunity for accelerated economic development of regional economies. The increasing number of new integration associations confirms that such a mechanism as a whole leads to a positive effect, both for the participating country and for the economic entity. A prerequisite for the basis of such associations is the prospect of improving the economic results of the participating countries, due to mutually beneficial cooperation. The Eurasian Economic Union conducts its activities relatively recently and is of interest not only to its neighboring countries, but from the entire international community. The paper discusses issues and prospects for the development of the Eurasian Economic Union. In this situation, the analysis of problems, factors that have the greatest influence on the development of economic cooperation of the countries of the Eurasian Economic Union is relevant. The paper notes that in the field of foreign trade of the Eurasian Economic Union there is a significant decline in trade turnover. It can be concluded that there is a separate quantitative increase in the indicators of economic cooperation of the participating countries, but there are not enough grounds for long-term stable economic development of these relationships. The potential of the Eurasian Economic Union is not used to the extent that this would be possible, and the experience of other countries confirms this to us.
\end{abstract}

Keywords: development, integration, EAEU, economic growth, cooperation

В современном мире международная экономическая интеграция стала инструментом ускоренного развития региональных экономик и повышения конкурентоспособности на мировом рынке стран - членов интеграционных объединений. Международная экономическая интеграция - это процесс, который предполагает срастание экономик соседних стран в единый хозяйственный комплекс, основанный на устойчивых экономических связях между хозяйствующими субъектами. Одним из важных моментов в этом процессе является экономика, так как основным мотивом таких объединений являются экономические интересы.

\section{Экономическая интеграция в мире}

Экономическая интеграция представляет собой процесс экономического взаи- модействия стран, в широком смысле этого понятия. Такая интеграция приводит к сближению хозяйственных механизмов, принимает форму межгосударственных соглашений и согласованно регулируется национальными или межгосударственными органами. Из наиболее крупных международных региональных интеграционных экономических структур можно выделить: ЕС (Европейское сообщество); НАФТА (Североамериканское соглашение о свободной торговле); АСЕАН (Ассоциация государств Юго-Восточной Азии); КАРИКАМ (Карибское содружество и общий рынок); СНГ (Содружество независимых государств); МЕРКОСУР (торговый союз стран Южной Америки); ЕАЭС (Евразийский экономический союз). Основной целью создания всех международных экономических объедине- 
ний является развитие экономик их членов, с помощью унификации форм регулирования экономических отношений. Одним из таких механизмов реализации национальных экономических интересов для России стало образование Евразийского экономического союза (ЕАЭС).

При этом существует один интересный момент, который необходимо учитывать, то, что многие страны являются членами Всемирной торговой организации (ВТО). Россия вступила в ВТО в августе 2012 г., условия соглашений при вступлении в ВТО прорабатывались в течение пятнадцати лет. Некоторые отрасли экономики станы были готовы к вступлению в ВТО ещё в 2003 г., однако с учетом интересов менее экономически развитых отраслей процесс присоединения к ВТО растянулся на многие годы [1]. Вступление в ВТО несло в себе как положительные, так и отрицательные моменты, поэтому процесс согласования занял так много лет. При этом основными преимуществами, которые выделяются при вступлении любого государства в ВТО, являются: выход в международное правовое пространство, выход на новые внешние рынки, усиление конкуренции между отечественными и зарубежными производителями, принятие общих правил торговли, в результате чего выигрывает отечественный потребитель. Если рассматривать экономический потенциал созданного объединения, необходимо отметить, что в настоящее время общая численность населения стран входящих в ЕАЭС составляет 182,748 млн чел. [2]. При этом макроэкономический эффект от объединения этих стран должен достигаться за счет таких факторов, как: снижение стоимости товаров за счет уменьшения издержек на перевозки; увеличение объемов производства в связи с увеличением спроса на товары; повышение благосостояния населения стран ЕАЭС за счет снижения цен на продукты и повышения занятости населения; ускорение окупаемости новых технологий в связи с увеличенным объемом рынка. Преимущество ЕАЭС в том, что это объединение основано не только на существующих экономических связях, но и историческом прошлом. При этом эффективность деятельности любого интеграционного объединения напрямую зависит от экономического эффекта для каждого участника.

\section{Евразийский экономический союз (ЕАЭС)}

Таможенный союз, в соответствии с Договором о ЕАЭС - это форма торгово-экономической интеграции государств-членов, предусматривающая единую таможенную территорию, в пределах которой во взаимной торговле не применяются таможенные пошлины (иные пошлины, налоги и сборы, имеющие эквивалентное действие), меры нетарифного регулирования, специальные защитные, антидемпинговые и компенсационные меры, действует Единый таможенный тариф Евразийского экономического союза и единые меры регулирования внешней торговли товарами с третьей стороной [3]. Ввозные таможенные пошлины, поступающие в ЕАЭС, распределяются между странами в соответствии с Договором о ЕАЭС (табл. 1).

Таблица 1

Нормативы распределения таможенных пошлин ЕАЭС

\begin{tabular}{|c|l|c|}
\hline $\begin{array}{c}\text { № } \\
\text { п/п }\end{array}$ & \multicolumn{1}{|c|}{ Страна } & $\begin{array}{c}\text { Доля от сумм вво- } \\
\text { зных пошлин, } \%\end{array}$ \\
\hline 1 & Российская Федерация & 85,32 \\
\hline 2 & Республика Беларусь & 4,56 \\
\hline 3 & Республика Казахстан & 7,11 \\
\hline 4 & Кыргызская Республика & 1,11 \\
\hline 5 & Республика Армения & 1,9 \\
\hline
\end{tabular}

Пр и м ечан и е. Источник: Договор о Евразийском экономическом союзе.

Как мы видим, основная часть таможенных поступлений приходится на Российскую Федерацию - 85,32\%, такое соотношение распределяется пропорционально вкладу страны в торговый оборот ЕАЭС. Например, доля торгового оборота Российской Федерации в объеме внешней торговли стран ЕАЭС составляет в 2016 г. 84,3\%, по отношению к 2012 г. этот показатель увеличился, но незначительно (табл. 2).

Таблица 2

Вклад стран в общий объем (оборот) внешней торговли ЕАЭС в 2012-2016 гг., \%

\begin{tabular}{|c|c|c|c|c|c|c|}
\hline $\begin{array}{c}\text { № } \\
\text { п/п }\end{array}$ & \multicolumn{1}{|c|}{ Страна } & 2012 & 2013 & 2014 & 2015 & 2016 \\
\hline 1 & $\begin{array}{l}\text { Российская } \\
\text { Федерация }\end{array}$ & 82,6 & 83,3 & 83,3 & 83,5 & 84,3 \\
\hline 2 & $\begin{array}{l}\text { Республика } \\
\text { Беларусь }\end{array}$ & 5,0 & 4,2 & 4,4 & 5,0 & 4,8 \\
\hline 3 & $\begin{array}{l}\text { Республика } \\
\text { Казахстан }\end{array}$ & 11,5 & 11,5 & 11,3 & 10,4 & 9,5 \\
\hline 4 & $\begin{array}{l}\text { Кыргызская } \\
\text { Республика }\end{array}$ & 0,4 & 0,5 & 0,5 & 0,5 & 0,7 \\
\hline 5 & $\begin{array}{l}\text { Республика } \\
\text { Армения }\end{array}$ & 0,5 & 0,5 & 0,5 & 0,6 & 0,7 \\
\hline & ВСЕГО & 100 & 100 & 100 & 100 & 100 \\
\hline
\end{tabular}

Пр и мечан и е. Источник: Внешняя торговля товарами. Статистика Евразийского экономического союза. 2016 г.: Статистический сборник [4]. 
Несмотря на нестабильную экономическую ситуацию, за последние годы объем взаимной торговли стран ЕАЭС увеличился на $26,1 \%$, в денежном выражении на 11 196,86 млн долл. США (табл. 3). В таких странах, как Казахстан, объем торговли со странами ЕАЭС за один год увеличился на $30,2 \%$ (на 1188,183 млн долл. США), а в Армении на 41,0\% (на 161,305 млн долл. США). Сравнивая долю этих стран во взаимной и внешней торговле, можно сказать, что членство в ЕАЭС для них действительно имеет экономическую выгоду, объем внешней торговли показывает отрицательную динамику, в то время как в сфере взаимной торговли происходит значительный рост, более $19 \%$ за год для всех стран $[5,6]$. Степень интеграции стран ЕАЭС имеет четкую тенденцию к росту. Рассмотрев структуру взаимной торговли стран ЕАЭС, мы увидим, что двумя основными торговыми группами в 2017 г. для России были минеральные продукты, машины, оборудование и транспортные средства $(36,9 \%$ и $16,7 \%)$.

Как правило, страны с сопоставимым уровнем экономического развития при либерализации внешней торговли, а рассматривая ЕАЭС именно снятие тарифных ограничений во взаимной торговле для стран-участников является либерализаци- ей их внешней торговли, значительно выигрывают от специализации на экспорте и импорте продукции одинаковых отраслей. В случае если же мирохозяйственные связи между интегрирующимися странами характеризуются только межотраслевым обменом, то они непрочны и подвержены частым конъюнктурным изменениям. Образовавшееся свободное экономическое пространство для передвижения товаров и капитала объединяет страны с различными условиями ведения хозяйственной деятельности. Если в отношении третьих стран установлены правила обязательные для выполнения всем участниками ЕАЭС, то в отношении налоговой политики внутри страны у каждого участника работает свое законодательство [7-9]. Различия не только в структуре налоговых платежей, взимаемых с юридических и физических лиц, но и в величине налоговых ставок по одноименным налогам. Например, налог на прибыль в Российской Федерации составляет $20 \%$, в Республике Беларусь $18 \%$, а в Казахстане $15 \%$. Если рассматривать налог на добавленную стоимость (НДС), то в Российской Федерации, Беларуси и Армении ставка одинаковая с 2019 г. и составляет $20 \%$ (по основной группе товаров), а в Казахстане и Кыргызской Республике ставка НДС - $12 \%$ (табл. 4).

Объем взаимной торговли стран ЕАЭС, млн долл. США

Таблица 3

\begin{tabular}{|c|l|c|c|c|c|}
\hline $\begin{array}{c}\text { № } \\
\text { п/П }\end{array}$ & \multicolumn{1}{|c|}{ Страна } & 2016 & 2017 & $\begin{array}{c}\text { Доля в 2017 г. } \\
\text { к объему,\% }\end{array}$ & $\begin{array}{c}\text { Темп прироста, } \\
\%\end{array}$ \\
\hline 1 & Российская Федерация & 26804,321 & 34329,342 & $63,4 \%$ & $+28,1 \%$ \\
\hline 2 & Республика Беларусь & 11384,797 & 13586,321 & $25,1 \%$ & $+19,3 \%$ \\
\hline 3 & Республика Казахстан & 3930,164 & 5118,347 & $9,5 \%$ & $+30,2 \%$ \\
\hline 4 & Кыргызская Республика & 447,173 & 568,008 & $1,0 \%$ & $+27,0 \%$ \\
\hline 5 & Республика Армения & 393,893 & 555,198 & $1,0 \%$ & $+41,0 \%$ \\
\hline & ВСЕГО & 42960,349 & 54157,209 & 100 & $+26,1 \%$ \\
\hline
\end{tabular}

П р и м е ч а н и е . Источник: Евразийский экономический союз. Официальный сайт [7].

Основные налоговые ставки стран ЕАЭС

Таблица 4

\begin{tabular}{|c|l|c|c|c|c|}
\hline $\begin{array}{c}\text { № } \\
\text { п/П }\end{array}$ & \multicolumn{1}{|c|}{ Страна } & $\begin{array}{c}\text { Налог } \\
\text { на прибыль }\end{array}$ & $\begin{array}{c}\text { Налог на добавлен- } \\
\text { ную стоимость }\end{array}$ & $\begin{array}{c}\text { Налог на доходы } \\
\text { физических лиц }\end{array}$ & $\begin{array}{c}\text { Страховые } \\
\text { взносы }\end{array}$ \\
\hline 1 & Российская Федерация & $20 \%$ & $18 \%$ & $13 \%$ & $30 \%$ \\
\hline 2 & Республика Беларусь & $18 \%$ & $20 \%$ & $12 \%$ & $29 \%$ \\
\hline 3 & Республика Казахстан & $15 \%$ & $12 \%$ & $10 \%$ & $11 \%$ \\
\hline 4 & Кыргызская Республика & $10 \%$ & $12 \%$ & $10 \%$ & $17,25 \%$ \\
\hline 5 & Республика Армения & $20 \%$ & $20 \%$ & $23 \%$ & $5 \%$ \\
\hline
\end{tabular}


При этом надо отметить, что между странами - участниками ЕАЭС при взаимной торговле предусмотрено применение нулевой ставки НДС и освобождение от уплаты акциза при экспорте. При этом установлен единый порядок взимания налогов, предусматривающий уплату НДС в бюджет страны импортера при ввозе товаров юридическими лицами и индивидуальными предпринимателями. НДС уплачивается импортером, впоследствии он может быть принят к вычету. При перемещении товаров без передачи права собственности НДС уплачивать не нужно. Это актуально для хозяйствующих субъектов, ведущих свою деятельность в разных странах членах ЕАЭС. Вопросы, связанные с двойным налогообложением по НДС, возникавшие при ввозе физическими лицами легковых автотранспортных средств, в настоящее время устранены. При значительных различиях в налогообложении и ведении бизнеса возможно возникновение эффекта, когда быть налоговым резидентом будет выгодно в какой-то одной стране. Такое положение может привести к тому, что произойдет перерегистрация компаний на территорию с более льготным режимом налогообложения. Вопрос гармонизации налогового законодательства, в ЕАЭС является одним из приоритетным. В Договоре о ЕАЭС вопрос налогообложения частично регулируется. Первоначально гармонизация налоговых платежей должна происходить в области налогов, имеющих непосредственное отношение к пересечению границ стран-участниц, это таможенные пошлины, НДС, акцизы и т.п. Установленный в 2012 г. Единый таможенный тариф Таможенного союза действует в настоящее время для ввоза товаров из стран не входящих в ЕАЭС и способствует существенному выравниванию величины таможенных платежей на территории ЕАЭС. Без создания Единого таможенного тарифа было бы невозможно сформировать ни экономический союз, ни Таможенный, так как таможенный тариф имеет важнейшее значение при регулировании внешнеторговых операций и является классическим инструментом государственного регулирования. Перенос оформления таможенных документов на внешние границы Таможенного союза и, как следствие, границы ЕАЭС, предоставил возможность для логистических компаний формировать новые маршруты.

Эффект от проводимой на национальном уровне экономической политики в отношении всех отраслей экономики будет преумножаться только в том случае, если она будет синхронизирована с политикой стран ЕАЭС.
Для создания масштабного экономического эффекта от сотрудничества в рамках ЕАЭС необходимо не только гармонизировать законодательство, но и создавать взаимовыгодные проекты не в рамках границ отдельного государства, а в границах всего ЕАЭС [10, 11]. Например, формирование единого технологического пространства ЕАЭС способно дать стимул для проектов, укрепляющих стабильное экономически выгодное сотрудничество. По оценкам Евразийской экономической комиссии, в государствах ЕАЭС сегодня действует более 200 индустриальных парков, примерно столько же технопарков, свыше 200 бизнес-инкубаторов, более 50 инновационных и промышленных кластеров [12]. По мнению Евразийской экономической комиссии, на основании разработанной ими системы индикаторов интеграции, по уровню интеграции ЕАЭС уже опережает такие группировки, как МЕРКОСУР и АСЕН, которые образовались более 30 лет назад. Проведенный анализ экономических взаимосвязей и взаимозависимостей национальных экономик взаимной торговли товарами и услугами показывает, что степень интеграции экономик имеет положительную тенденцию роста и отвечает целям, поставленным при создании ЕАЭС. За время существования ЕАЭС, можно отметить определенные достижения, к которым можно отнести присоединение двух новых членов (Армения и Кыргызстан), принятие Таможенного кодекса ЕАЭС, принятие концепции по формированию общего энергетического рынка, обеспечение свободного передвижения рабочей силы, принятие основных этапов реализации транспортной политики.

\section{Заключение}

Область формирования единого рынка услуг, то есть формирования пространства определенного сектора услуг, в котором не применяются количественные, дискриминационные или другие ограничения, является одним из приоритетных направлений в развитии ЕАЭС. Создание единого рынка труда дало возможность платить нерезидентам стран ЕАЭС налог на доходы по той же налоговой ставке, что и резиденты. Проведенное исследование позволяет сделать вывод, что наблюдается отдельное количественное увеличение показателей экономического сотрудничества странучастников, но недостаточно оснований для стабильного экономического развития этих взаимоотношений. Потенциал Евразийского экономического союза пока не используется в той мере, в которой это было бы возможно, и опыт других стран нам это подтверждает. Актуален вопрос не только 
совместных проектов, но и в первую очередь необходимость гармонизации налогового законодательства и поддержки предпринимательства со стороны государства во всех странах - членах ЕАЭС. При этом для укрепления экономического сотрудничества необходимо продолжать проводить единую стратегию развития, в том числе в промышленности, сельском хозяйстве, транспортном развитии и импортозамещении на общем рынке.

\section{Список литературы}

1. Асаул М.А., Мохов А.Е. Формирование единого транспортного пространства и общего рынка транспортных услуг в ЕАЭС // Транспорт Российской Федерации. 2018. № 2 (75). С. 6-9.

2. Страны и города // Информационной портал. [Электронный ресурc]. URL: http://infotables.ru/strany-i-goroda/17tablitsa-chislennost-naseleniya-stran-mira (дата обращения: 30.06.2019).

3. Чириканова Е.А. Тенденции развития производства автомобильных компонентов на территории России в связи со вступлением во Всемирную торговую организацию // Автотранспортное предприятие. 2013. № 7. С. 21-24.

4. Договор о Евразийском экономическом союзе // Министерство экономического развития Российской Федерации. Официальный сайт. [Электронный ресурc]. URL: http:// economy.gov.ru/minec/ about/structure/depSNG/agreement-eurasian-economic-union (дата обращения: 30.06.2019).

5. Евразийская экономическая комиссия. Внешняя торговля товарами. Статистика Евразийского экономического союза. 2016 год: Статистический сборник. М.: ООО «Сам Полиграфист», 2017. $516 \mathrm{c}$.

6. Улицкий М.П., Хмельницкий А.Д. Модернизация управления объектами транспортной инфраструктуры// Вестник Московского автомобильно-дорожного государственного технического университета (МАДИ). 2012. № 4 (31). С. 31-37.

7. Евразийский экономический союз. Официальный сайт // Департамент статистики. [Электронный ресурс]. URL: http://www.eurasiancommission.org/ru/act/integr i makroec/dep stat/tradestat/time series/Pages/default.aspx (дата обращения: 30.06.2019).

8. Улицкий М.П., Чириканова Е.А. Изменения таможенных пошлин на автотранспортные средства в границах Таможенного союза // Вестник Московского автомобильнодорожного государственного технического университета (МАДИ). 2012. № 1 (28). С. 85a-90.

9. Подхалюзина В.А., Дрейцен М.А. Научно-методические подходы оценки современного состояния транспорта региона // Транспортное дело России. 2017. № 2. C. $56-57$.

10. Чириканова Е.А. Экономические изменения налогообложения транспортных средств в Российской Федерации // ЭТАП: экономическая теория, анализ, практика. 2017. № 3. C. 111-119.

11. Телушкина Е.К., Телушкин А.А. Опыт словацких автопроизводителей по преодолению негативных последствий мирового финансового кризиса 2008-2009 гг. // Горизонты экономики. 2015. № 1 (20). С. 73-77.

12. Васильева Ю.И. Меры по усилению контроля налоговыми органами // Национальные и международные финансово-экономические проблемы автомобильного транспорта сборник научных трудов. М.: Московский автомобильно-дорожный государственный технический университет (МАДИ), 2018. С. 117-121. 